\title{
Innovative Exploration of Dance Teaching with Students as the Main Body in Dance Teaching in Colleges and Universities
}

\author{
Zhou Lu \\ Qiongtai Normal University Hainan Haikou, 571127
}

Keywords: students as the main body; dance teaching in Colleges and universities; innovation

\begin{abstract}
Chinese traditional culture, dance culture occupies an important proportion and status in it. In recent years, with China's importance in the field of culture continues to improve, each university dance teaching work also in the unceasing reform, but in actual dance teaching, many teachers still use the traditional teaching mode in the teaching work, this to a certain extent for students learning to dance is very unfavorable. In this paper, the author takes dance teaching as the breakthrough point, and actively explores the student oriented dance teaching in college dance teaching innovation exploration.
\end{abstract}

\section{Introduction}

Most of the traditional dance education is to train the students' physical fitness as the main content, to teach the students to learn the dance moves in the dance teaching work mostly with the teacher as the leading position, fundamentally ignores students' learning subjectivity, thus is unable to improve the students learning level to the dance. With the teacher as the leading position, emotion and spirit to enable students to fully understand the dance, even if there is a lot of dance students, so can not be their own dance performance of the play out. Therefore, teachers must respect the initiative of students in the teaching process, so that students in learning to dance in the creation of independent learning, to better improve students' understanding ability of dance has the efficiency and quality of learning dance.

\section{The traditional dance teaching model in Colleges and Universities}

The curriculum arrangement of many universities in China will be arranged according to the number of students enrolled every year. When actively carry out the work of teaching, many colleges and universities generally have modern teaching equipment is not perfect, and there are some schools do not have strength enough to improve teachers' teaching, which will seriously affect the school personnel training plan. Many colleges and universities are the dance class set for elective courses, and even a lot of dancing is a form of existence, and not enough to teach the students to learn dance knowledge, did not play the advantages and role of customers five fundamentally. Some schools will rarely dance elective course schedule, a Monday only one lesson, the students in this case is not enough good dance learning conditions, a long time will make students lose their learning enthusiasm and enthusiasm to the dance, and do not pay enough attention to meet learning, learning dance just to think to deal with the school elective course. The teacher in the teaching of dance using teaching methods not correct, can be the basis of the dance to teach the students the knowledge, the whole process ignores the cultivation of students' ability to listen to music, using more traditional teaching methods and old teaching, for students to learn dance has certain influence [1].

\subsection{The teaching mode is rigid, and the teaching content is not innovative}

In the process of running colleges and universities, many colleges and universities dance teaching curriculum is relatively late, dance teaching work is often subject to the constraints of the teachers. Many colleges and universities set up dance teaching courses, are the use of key art institutions dance curriculum settings, dance teaching standards and examination standards are 
based on the key dance institutions dance standards as the basis. The students who choose to learn dance are generally relatively low in cultural courses, and some students may not have enough powerful dance base, which will lead to the basic level of the students who are admitted to the university when they recruit students. Some college teachers in teaching students to understand the actual situation, no learning students waved deeply from the root, when used in the teaching way are other excellent colleges teaching methods, students can not meet the needs of learning dance fundamentally, it makes students to dance movement to reach a certain standard, may even have a certain weariness, to resist dance learning [2].

\subsection{We must first take the student as the main body of education idea}

Dance itself has a certain art, dance from the students' daily life, but the real meaning of Plateau and life, dance pay more attention to the expression and creativity of artistic conception, is a very artistic charm of artistic behavior. In the whole process of dance teaching, teachers should fully follow the students' learning principal position, take the basic learning needs of students as the starting point, and establish different activities. Most of the students' experience and feelings about dance are derived from the attitude of learning dance. If you want to fundamentally improve the students' dance learning level, then the first important problem should let students feel the inherent charm of dance culture fundamentally, so that students can maximize the charm of dancing. If the dance is divorced from practice and exploration process, then students can not grasp the connotation of dance. The process of students' development and creation is actually an independent learning process. The teacher led the students in learning the dance teaching, the main content is not to tell the students what kind of posture is correct, what kind of dance posture is wrong, but to actively encourage students to explore the creative process of dance, to create a new dance posture according to my own experience of learning dance in which, not only into their subjective emotion but also integrate development elements of the new era, the only way to maximize students' comprehension of the conception of the dance. If teachers pay enough attention to students' dance learning subjectivity in teaching, they can give full play to students' dance learning effect [3].

\subsection{The application of independent concept in dance teaching}

Many teachers work in the field of dance have a dance and dance certain qualifications, the backbone of teachers in the process of work to distinguish who is the main body status in the teaching process will be regarded as the subject of students in the learning process, the subject of students' consciousness with cognition and enough attention thus, it make students have a very strong initiative in the learning process. Cultivating students' subjective consciousness of learning can not only help students master enough dance movements, but also lead students to feel the spirit and connotation of dance. The teacher should demonstrate the dance movements for the key dance movements and difficulties, and guide the students to imitate the movements of the teachers to learn the dance movements, so as to improve the students' learning achievements in dance.

\section{Dance teaching innovation with students as the main body}

The students as the dominant position in the learning activities, are very important for each teaching stage and teaching work, relates to the whole teaching process of colleges and universities, students' subjective consciousness as students age changing, therefore, when actively promote teaching must respect the students the main body position. Only by fundamentally determining the importance of students learning subject, can maximize the students into the actual dance teaching work. In the study, teachers should fully grasp the students' age characteristics and learning characteristics, the only way to enable students to better feel the dance brought about by the dynamic and passion. The process of teaching dance, change traditional change in the status of teachers and students to a certain extent depends on the status of teaching subject, when teachers should conduct in the teaching work actively to the dominant position of students as an important teaching content, which means that teachers should continuously improve the level of self teaching, bring adequate learning facilities for students, so that students can continue to have the confidence 
to improve the dance learning level, so it can ensure the high school dance teaching work can proceed smoothly [4].

This dance course learning not only adequate theoretical knowledge, but also need high intensity physical training in the process of limb training should also properly combine students' subjective emotion, dance course itself is a complicated process of trouble work, only to guide students to music and body training perfect fusion, can appeal to enable students to better feel the charm of dance and dance. To cultivate students' positive dance emotion and dance body training for students' development has a very important role, can let students maintain a certain degree of confidence and logic to face the dance learning, to maximize the stimulation of students' spiritual learning potential. When students dance practice in the application of music and physical training, is not able to with their own emotional experiences are separated, only to enhance the students' inner cognitive ability for the art of dance, to enable students to devote more energy and enthusiasm to learn dance. The smooth progress of emotional education can not only promote the emotional communication and communication between teachers and students, but also guide and encourage students to learn dance in a healthy and upward direction.

The traditional dance teaching mode, excessive attention to students' dance skills and body language in dance training, which also ignored students to exercise in the process of teaching the art of dance creation ability, so the traditional dance teaching too much emphasis on external things, make the teaching process and learning process become the lack of dance activity. Living in a new era, in order to promote the physical and mental health of students in Colleges and universities to exercise smoothly, the school should strictly grasp the development needs of today's college students, according to the different learning needs of college students and develop different dance teaching plan. The task of teaching in Colleges and universities is to enable students to learn enough knowledge at the same time, but also can exercise extreme physical and mental health of students, and promote students to healthy development. The cultivation of students' personality in a certain extent can be achieved through dance learning through music, rhythm and melody can make students' inner feeling of restraint decreased, make students mind becomes calm, so also played an essential role in dance teaching, lay a positive force for the development of students' daily and benign the development of the future [5].

In the process of teaching, with the most basic dance rhythm and action as teaching material, help students to establish a professional learning group, guide students to group creation. The creation of introducing competition mechanism, to a certain extent, can effectively stimulate students' psychological, to mobilize the participation and enthusiasm of students, so that students will be able to maximize their initiative to play. In the process of creative learning, students can not only harvest a lot of joy and dance knowledge, but also can constantly improve their self-learning ability, develop good learning habits. Application of the teaching method of creative teaching on students' dance competition, the main teaching work is through the creation of a certain dance scene, to lead the students to participate in the context of the completion of the goal and task of learning in students' dance, when creating dance movements have a certain time limit, that is to say within the prescribed period of time to see which group of students can complete the tasks in accordance with limited objectives, to complete the task of the group should make appropriate incentives, and the bad team should make appropriate criticism. According to the related data research shows that the students under the state of competition, the students' learning efficiency and learning quality to be much higher than the previous high under the state of competition, even in the face of dull as ditch water dance knowledge, students are able to mobilize their enthusiasm for learning, will be your greatest effort into learning to dance, to improve their dancing skills.

Generally speaking, problems are often a starting point of thinking development. Paying attention to the problem can cultivate students' subjective consciousness well, and paying attention to the problem is also an important teaching method of innovative quality. The teacher organization, and encourage students to explore and study the learning process of the dance, to help lead the students to understand the characteristics of different dance styles and dance movements, after learning sufficient knowledge in students to dance, dance moves constantly practice, theory and 
practice are combined very well to stimulate dance students initiative innovation ability, at the same time in the process of learning, it can achieve the dominant position of students better advantage. The application of heuristic thinking teaching method in dance teaching is an important teaching content, in fact, it is to lead students to explore dance, teachers should be good at inspiring students and guide students, for students to do the right direction guidance role. Through continuous observation and analysis, students can better find the rules and characteristics of dance in the process of dance learning, so as to summarize their own style of dance. The creation of problem dance should be thinking highly, when creating the problem to take into account the student's ability to dance and mastery of dance knowledge, scientific setting for dance students, to mobilize students to explore and learn to dance dance enthusiasm interest, so as to continuously enhance the innovation ability of students to dance [6].

\section{Conclusion}

The development of dance teaching in Colleges and universities has been continuously recognized and supported by all walks of life. At the same time, many students begin to praise and accept this unique teaching mode. In many colleges and universities have already formed independent dance associations and other organizations, for the school dance teaching has brought some favorable conditions. The teaching mode of taking students as the main body of teaching has improved the influence and appeal of dance teaching to a certain extent, and at the same time promoted the quality education work of colleges and universities to go on smoothly. The students will inevitably encounter some problems in learning dance teacher, in this case, the teacher should lead to the right of students, help students to practice and exploration of dance, in order to improve students' dance learning, school dance teaching task.

\section{References}

[1] Zhao Yonglin. On the integration of dance teaching and dance culture market in Colleges and universities [J]. art evaluation, 2016, (02): 122-123.

[2] Meng Chao. Innovative research on dance teaching with students as the main body in college dance teaching [J]. popular literature and art, 2016, (11): 213.

[3] Zhao Yonglin. Research on the reform path and development strategy of dance teaching in Colleges and universities [J]. art evaluation, 2016, (01): 159-160.

[4] Kong Yan. Innovative research on dance teaching with students as the main body in college dance teaching [J]. popular literature and art, 2015, (09): 246-247.

[5] Bi Y. Exploration in Dance Teaching in the Major of Preschool Education[J]. Asian Journal of Social Science, 2011, 7(6).

[6] Liu R. Analysis on Measures to Promote the Development of Innovative Dance Teaching in Colleges and Universities[J]. Journal of Hubei Correspondence University, 2016.

Lu Zhou Female, Hunan province, January 7th,1983, MFA, Qiongtai Normal University, Associate professor, Choreography of dance, Ddance education 